\title{
Analysis on the Input-Output Relevancy between China's Financial Industry and Three Major Industries
}

\author{
Jia-li Cai ${ }^{1}$ \\ ${ }^{1}$ College of Economics and Management, Nanjing University of Aeronautics and Astronautics, Nanjing, China \\ Correspondence: Jia-li Cai, College of Economics and Management, Nanjing University of Aeronautics and \\ Astronautics, Jiangjun Road 29\#, Jiangning District, Nanjing City, Jiangsu Province, China. Tel: \\ 86-187-6240-6638. E-mail: caijiali92@163.com
}

Received: April 16, 2016

doi:10.5539/ijef.v8n7p294
Accepted: May 3, 2016

Online Published: June 25, 2016

URL: http://dx.doi.org/10.5539/ijef.v8n7p294

\begin{abstract}
Finance is the core of modern economy, which plays an important role of allocating the resources and regulating the economy. The input-output table of China in 2007 and 2010 will be integrated into a simple form which includes primary industry, secondary industry, tertiary industry and the financial industry in this paper. Through the analysis on the direct dependency, complete dependency, spread effect and intermediate input rate and output rate, this paper investigates the relevancy between China's financial industry and three major industries. It is concluded that although China's financial industry develops rapidly, its status and role in the national economy is not outstanding. And this paper gives some suggestions for the development of the national economy, including developing the tertiary industry, promoting the structure upgrade of secondary industry and speeding up the cultivation of financial talents to promote the development of the financial industry.
\end{abstract}

Keywords: financial industry, three major industries, input-output analysis, industry relevancy, spread effect

\section{Introduction}

\subsection{Research Background and Significance}

Finance is the core of modern economy, which plays an important role of allocating the social resources and regulating the national economy. Its level of development and industrial structure directly affect the degree of a country's economic stability.

In 2007, the outbreak of the financial crisis swept across the whole world in an unprecedented situation, greatly impacting the distribution pattern of global finance. How to coordinate the relationship between the financial industry and the other industries once again aroused the attention of the whole world. Each country took the structure upgrading of financial industry and the construction of smooth financing channels as the dominant theme of the national economy.

Financial industry connects between each social industry. On the one hand, the production of each industry needs financial services; On the other hand, the financial industry as a high debt industry, its development also needs support from the real economy. Therefore, there are not only direct links between the financial industry and the other industries, but also lots of indirect links between each other.

China's financial industry develops relatively late, so there are considerable gaps in the level of development and the rationality of industrial structure with developed countries. There are some defects in the development of China's financial industry, such as diseconomies of scale, imbalance of industrial structure and lacking an enough role of promoting the national economy. China is in the stage of economic transition, so how to grasp the opportunity to improve the industrial structure of the financial industry and strengthen its role of promoting the other industries has become a very important task.

Therefore, using the method of input-output analysis to analyze the relevancy between the financial industry and three major industries not only has the theoretical support, but also has a very important practical significance.

\subsection{Literature Review}

Economist Wassily Leontief (1936) established the input-output model and used it to study the input-output relevancy between the various industries in a country's economic system. In the 1960s, British professor John 
Richard applied the input-output method in the study of financial industry for the first time. John Richard made the input-output table of financial industry and used it to study the financial links between various industries.

Based on the research in foreign countries, China's input-output research began in the 1960s and the input-output table was compiled every five years since 1987. Shou-yi Zhang (1988) compiled an embedded input-output table to analyze the impact of the optimal structure on each national economic sector. Xi-kang Chen (1991) compiled the "input-occupancy-output table on China's urban and rural economy", adding the vector of production factor to make the table contain more information. Zhan-qi Yao (2005) studied the industrial relevancy between the financial industry and the secondary industry, together with the tertiary industry in China. And he made a comparison of China's financial industrial relevancy between the developed countries, finding that the financial industry is closely related to the service industry in the developed countries, while is closely related to the manufacturing industry in China. Ming Li (2010) used the input-output table in 2007 in Anhui province to analyze the role of the financial industry to the development of the economy in Anhui province and found that the financial industry was not widely involved in other industries, especially the secondary industry. Mei-dong Qi (2011) used the input-output model to prove the important promotion of the financial industry for the circular economy and proposed the policy recommendations to build a financial supporting system which is market-oriented and takes the finance as its main body for the circular economy. Shi-gai Chai (2013) analyzed the technical and influence foundation of industry finance. This paper built the influence coefficient and sensitivity coefficient to analyze the interaction effects of industry finance and other sectors respectively and found that the financial industry developed quietly independently. Jie Bai (2014) used the input-output table in 2007 in Jiangsu province to analyze the direct influence and complete influence of the financial industry on Jiangsu's economy and found that the financial industry was the important part of Jiangsu's economic system, but its promoting role to the economy was weak.

Based on the previous research, this paper studies the input-output relevancy between the financial industry and the three major industries in China by establishing the simple form of the input-output table and computing the correlation coefficient matrix.

\section{Introduction to the Industry Relevance Theory}

Industry relevance theory is the theory studying the technical and economic links and industrial input-output quantitative relevancy between the industries. Industry relevancy refers to the technical and economic links based on the various input-output factors between the industries. Each industrial sector contributes products and services between each other, relates and constrains with each other, constituting the organic whole of the national economy.

There is a wide range of technical and economic relevancy between the industries and the relevancy approach is various. This paper mainly studies the direct and indirect relevancy between the industries. In addition, according to the technical directions and characteristics between the industries, it can be divided into one-way relevancy and multi-way relevancy; according to the supply and demand relationship between the industries, it can be divided into forward relevancy, backward relevancy and circular relevancy.

The direct relevancy and indirect relevancy between the industries are distinguished with each other based on the dependence of each industry. The so-called direct relevancy between the industries refers to the technical and economic relevancy based on the direct input of the factors of production for each other. The so-called indirect relevancy between the industries refers to the technical and economic relevancy between the two industries based on the other industries as intermediaries. The sum of the direct and indirect relevancy is known as the complete relevancy between the industries.

\section{Data Sources and Processing}

In this paper, the data was derived from China's input-output tables in 2007 and 2010. In order to study the relationships between the financial industry and the three major industries, this paper integrates the two tables in accordance with the principal of "pure departments", by integrating the input-output table into the form consisting of the primary industry, the secondary industry and the tertiary industry, with the financial industry separated from the tertiary industry (excluding financial industry from the tertiary industry), to form the two tables shown in Table 1 and Table 2. 
Table 1. China's I-O table in 2007 (Unit: Million Yuan)

\begin{tabular}{|c|c|c|c|c|c|c|c|c|}
\hline \multirow[b]{2}{*}{ Input } & \multirow[t]{2}{*}{ Output } & \multicolumn{5}{|c|}{ Intermediate Use } & \multirow[b]{2}{*}{ Final Use } & \multirow[b]{2}{*}{$\begin{array}{l}\text { Total } \\
\text { Outputs }\end{array}$} \\
\hline & & $\begin{array}{l}\text { Primary } \\
\text { Industry }\end{array}$ & $\begin{array}{l}\text { Secondary } \\
\text { Industry }\end{array}$ & $\begin{array}{l}\text { Tertiary } \\
\text { Industry }\end{array}$ & $\begin{array}{l}\text { Financial } \\
\text { Industry }\end{array}$ & $\begin{array}{c}\text { Total } \\
\text { Intermediate } \\
\text { Use }\end{array}$ & & \\
\hline \multirow{5}{*}{$\begin{array}{l}\text { Intermediate } \\
\text { Inputs }\end{array}$} & Primary Industry & 68771565 & 249167666 & 25500448 & 0 & 343439679 & 145490320 & 488930000 \\
\hline & Secondary Industry & 102596499 & 3647832322 & 469599904 & 12534841 & 4232563565 & 1543244915 & 5775808480 \\
\hline & Tertiary Industry & 26906576 & 457530730 & 286691544 & 35456998 & 806585848 & 922455052 & 1729040899 \\
\hline & Financial Industry & 4063622 & 76324961 & 52668267 & 12505567 & 145562416 & 49247824 & 194810240 \\
\hline & $\begin{array}{l}\text { Total Intermediate } \\
\text { Inputs }\end{array}$ & 202338262 & 4430855679 & 834460162 & 60497405 & 5528151509 & 2660438111 & 8188589620 \\
\hline \multirow{6}{*}{ Value-added } & Labor Reward & 271816270 & 459941924 & 333827065 & 34887741 & 1100473000 & & \\
\hline & Net Product Tax & 478020 & 270102903 & 99445624 & 15160686 & 385187233 & & \\
\hline & $\begin{array}{c}\text { Depreciation of Fixed } \\
\text { Assets }\end{array}$ & 14297448 & 181617238 & 174702367 & 1938269 & 372555322 & & \\
\hline & Operating Surplus & 0 & 433290736 & 286605680 & 82326139 & 802222556 & & \\
\hline & Total Value-added & 286591738 & 1344952802 & 894580737 & 134312835 & 2660438111 & & \\
\hline & otal Inputs & 488930000 & 5775808480 & 1729040899 & 194810240 & 8188589620 & & \\
\hline
\end{tabular}

Table 2. China's I-O table in 2010 (Unit: Million Yuan)

\begin{tabular}{|c|c|c|c|c|c|c|c|c|}
\hline \multirow[b]{2}{*}{ Input } & \multirow[t]{2}{*}{ Output } & \multicolumn{5}{|c|}{ Intermediate Use } & \multirow[b]{2}{*}{ Final Use } & \multirow[b]{2}{*}{$\begin{array}{c}\text { Total } \\
\text { Outputs }\end{array}$} \\
\hline & & $\begin{array}{l}\text { Primary } \\
\text { Industry }\end{array}$ & $\begin{array}{l}\text { Secondary } \\
\text { Industry }\end{array}$ & $\begin{array}{l}\text { Tertiary } \\
\text { Industry }\end{array}$ & $\begin{array}{l}\text { Financial } \\
\text { Industry }\end{array}$ & $\begin{array}{c}\text { Total } \\
\text { Intermediate } \\
\text { Use }\end{array}$ & & \\
\hline \multirow{3}{*}{$\begin{array}{l}\text { Intermediate } \\
\text { Inputs }\end{array}$} & Primary Industry & 92202500 & 404595539 & 42331039 & 0 & 539129077 & 154068923 & 693198000 \\
\hline & Secondary Industry & 150873610 & 5505067558 & 700015902 & 20224053 & 6376181123 & 2394105244 & 8770286368 \\
\hline & Tertiary Industry & 39271469 & 786175862 & 432144502 & 66923525 & 1324515358 & 1415583170 & 2740098528 \\
\hline \multirow[b]{3}{*}{ Value-added } & Labor Reward & 385628326 & 766230298 & 691620833 & 66609819 & 1910089276 & & \\
\hline & Net Product Tax & 783500 & 395917965 & 176855395 & 25551609 & 599108470 & & \\
\hline & $\begin{array}{c}\text { Depreciation of Fixed } \\
\text { Assets }\end{array}$ & 18924174 & 255441444 & 273633874 & 4919117 & 552918609 & & \\
\hline
\end{tabular}

\section{Analysis on the Linkage Effect between the Financial Industry and the Three Major Industries}

\subsection{Analysis on the Direct Dependency between the Financial Industry and the Three Major Industries}

The development of the financial industry needs to consume the products from the other industries directly; meanwhile the financial industry provides services for the development of the other industries. To grasp the role and the position of the financial industry in the economic system accurately, we need to analyze the direct effect of the financial industry on the national economy firstly. The direct consumption coefficient, intermediate input coefficient, initial input coefficient, direct labor reward coefficient, direct product tax coefficient, direct depreciation of fixed assets coefficient and the direct operating surplus coefficient are used to analyze the direct dependency between the financial industry and the three major industries in this paper. The calculation formula of each coefficient is as follows:

1). Direct Consumption Coefficient:

$$
a_{i j}=\frac{x_{i j}}{X_{j}}(i, j=1,2, \ldots n)
$$

2). Intermediate Input Coefficient:

$$
A c_{j}=\frac{\sum_{i=1}^{n} x_{i j}}{X_{j}}(j=1,2, \ldots n)
$$

3). Initial Input Coefficient:

$$
A g_{j}=\frac{V_{j}+T_{j}+D_{j}+M_{j}}{X_{j}}(j=1,2, \ldots n)
$$

4). Direct Labor Reward Coefficient: 


$$
A v_{j}=\frac{V_{j}}{X_{j}}(j=1,2, \ldots n)
$$

5). Direct Product Tax Coefficient:

$$
A t_{j}=\frac{T_{j}}{X_{j}}(j=1,2, \ldots n)
$$

6). Direct Depreciation of Fixed Assets Coefficient:

$$
A d_{j}=\frac{D_{j}}{X_{j}}(j=1,2, \ldots n)
$$

7). Direct Operating Surplus Coefficient:

$$
A m_{j}=\frac{M_{j}}{X_{j}}(j=1,2, \ldots n)
$$

\begin{tabular}{|c|c|c|c|c|c|}
\hline & & Primary Industry & Secondary Industry & Tertiary Industry & Financial Industry \\
\hline \multirow{4}{*}{$\begin{array}{c}\text { Direct Consumption } \\
\text { Coefficient }\end{array}$} & Primary Industry & 0.1407 & 0.0431 & 0.0147 & 0.0000 \\
\hline & Secondary Industry & 0.2098 & 0.6316 & 0.2716 & 0.0643 \\
\hline & Tertiary Industry & 0.0550 & 0.0792 & 0.1658 & 0.1820 \\
\hline & Financial Industry & 0.0083 & 0.0132 & 0.0305 & 0.0642 \\
\hline \multicolumn{2}{|c|}{ Intermediate Input Coefficient } & 0.4138 & 0.7671 & 0.4826 & 0.3105 \\
\hline \multicolumn{2}{|c|}{ Initial Input Coefficient } & 0.5862 & 0.2329 & 0.5174 & 0.6895 \\
\hline \multicolumn{2}{|c|}{ Direct Labor Reward Coefficient } & 0.5559 & 0.0796 & 0.1931 & 0.1791 \\
\hline \multicolumn{2}{|c|}{ Direct Product Tax Coefficient } & 0.0010 & 0.0468 & 0.0575 & 0.0778 \\
\hline \multicolumn{2}{|c|}{ Direct Depreciation of Fixed Assets Coefficient } & 0.0292 & 0.0314 & 0.1010 & 0.0099 \\
\hline \multicolumn{2}{|c|}{ Direct Operating Surplus Coefficient } & 0.0000 & 0.0750 & 0.1658 & 0.4226 \\
\hline
\end{tabular}

Using the data from the Table 1 and 2, and according to the above formulas, each input coefficient will be calculated and listed in Table 3 and 4.

\begin{tabular}{|c|c|c|c|c|c|}
\hline & & Primary Industry & Secondary Industry & Tertiary Industry & Financial Industry \\
\hline Direct Consumption & Primary Industry & 0.1330 & 0.0461 & 0.0154 & 0.0000 \\
\hline \multirow[t]{3}{*}{ Coefficient } & Secondary Industry & 0.2176 & 0.6277 & 0.2555 & 0.0626 \\
\hline & Tertiary Industry & 0.0567 & 0.0896 & 0.1577 & 0.2073 \\
\hline & Financial Industry & 0.0080 & 0.0149 & 0.0322 & 0.0803 \\
\hline \multicolumn{2}{|c|}{ Intermediate Input Coefficient } & 0.4153 & 0.7783 & 0.4609 & 0.3502 \\
\hline \multicolumn{2}{|c|}{ Initial Input Coefficient } & 0.5847 & 0.2217 & 0.5391 & 0.6498 \\
\hline \multicolumn{2}{|c|}{ Direct Labor Reward Coefficient } & 0.5563 & 0.0874 & 0.2524 & 0.2063 \\
\hline \multicolumn{2}{|c|}{ Direct Product Tax Coefficient } & 0.0011 & 0.0451 & 0.0645 & 0.0791 \\
\hline \multicolumn{2}{|c|}{$\begin{array}{c}\text { Direct Depreciation of Fixed Assets } \\
\text { Coefficient }\end{array}$} & 0.0273 & 0.0291 & 0.0999 & 0.0152 \\
\hline \multicolumn{2}{|c|}{ Direct Operating Surplus Coefficient } & 0.0000 & 0.0600 & 0.1223 & 0.3491 \\
\hline
\end{tabular}

Table 3. Direct dependency table in 2007

Table 4. Direct dependency table in 2010

Through the horizontal analysis of the direct consumption coefficient matrix in the above table, this paper investigates the promoting role of the financial industry to the other industries. In 2007, the largest direct effect of the financial industry to other industries is itself, the coefficient is 0.0642 . It means that every one unit product of the financial industry needs 0.0642 units of its own inputs. Except the financial industry itself, the rest is the tertiary industry $(0.0305)$, the secondary industry $(0.0132)$ and the primary industry $(0.0083)$. It shows that the financial industry has a largest impact on the tertiary industry and a weakest impact on the primary industry. This result conforms to the policy that develops the tertiary industry vigorously in China. In 2010, the financial industry still makes the largest effect on itself, and follows the tertiary industry, the secondary industry and the primary industry. The direct effect of the financial industry only declined slightly to the primary industry, the other two industries both raise. It shows that the financial industry plays an increasingly important role in the economic system. 
Through the longitudinal analysis of the direct consumption coefficient matrix in the above table, this paper investigates the promoting role of the other industries to the financial industry. The financial industry consumes 0.1802 units of the products from the tertiary industry, 0.0643 units of the products from the secondary industry, 0.0642 units of the products from the financial industry and 0 units of the products from the primary industry for every unit output in 2007. It shows that the development of the financial industry doesn't need the direct consumption of the products from the primary industry. In other words, the financial industry doesn't have a direct pulling impact on the primary industry. The financial industry consumes 0.2073 units of the products from the tertiary industry, 0.0803 units of the products from the financial industry, 0.0626 units of the products from the secondary industry and 0 units of the products from the primary industry for every unit output in 2010 . It shows that the financial industry makes an increasing pulling impact on itself and the tertiary industry, and the pulling impact decreases on the secondary industry. It can be seen that the development of the financial industry mainly needs the direct input from the tertiary industry, so improving the development of China's financial industry and developing the tertiary industry are two indivisible aspects.

The intermediate input coefficient of the financial industry is 0.3105 and the initial input coefficient is 0.6895 in 2007; the intermediate input coefficient is 0.3502 of the financial industry and the initial input coefficient is 0.6498 in 2010. It can be found that the intermediate input coefficient of China's financial industry is on the rise and the initial input coefficient is on the decline, and the intermediate input coefficient is far lower than the initial input coefficient, fully proved that the financial industry is a high value-added industry.

In the added-value coefficients, the direct operating surplus coefficient is the highest and is far higher than the other industries at the same period both in 2007 and 2010. It means that the financial industry is an industry of great economic benefit. The direct labor reward coefficient of the financial industry is also higher than the other industries. It means that the financial industry has a great need of the talent. So it is necessary to develop the new financial talent to promote the further development of the financial industry. The direct product tax coefficient is also higher than the other industries at the same period. It means that the development of the financial industry can make the national treasury solid so as to facilitate people's production and living.

\subsection{Analysis on the Complete Dependency between the Financial Industry and the Three Major Industries}

There are not only direct links between each industry of the national economy, but also a lot of indirect links. For example, the direct consumption coefficient between China's financial industry and the primary industry is 0 , but it doesn't mean that the development of the financial industry doesn't need to consume the products from the primary industry. As we can see, the production of the financial industry needs paper, and the production of paper needs the input of the primary industry, so as to make an indirect link between the financial industry and the primary industry. In this paper, the complete consumption coefficient is used to analyze the complete dependency between the financial industry and the three major industries. The calculation formula and the matrix form of the complete consumption coefficient are as follows:

$$
\begin{gathered}
b_{i j}=a_{i j}+\sum_{k=1}^{n} b_{i k} a_{k j}(i, j=1,2, \ldots n) \\
B=(I-A)^{-1}-I
\end{gathered}
$$

Using the above formula, the complete consumption coefficients are listed in the Table 5 and 6.

Table 5. Complete consumption coefficient in 2007

\begin{tabular}{ccccc}
\hline Industry & Primary Industry & Secondary Industry & Tertiary Industry & Financial Industry \\
\hline Primary Industry & 0.207257 & 0.1581196 & 0.0737454 & 0.0252149 \\
Secondary Industry & 0.8123965 & 2.043298 & 1.0200851 & 0.4076495 \\
Tertiary Industry & 0.1627867 & 0.3113176 & 0.3131112 & 0.2767965 \\
Financial Industry & 0.0274928 & 0.0545125 & 0.0578021 & 0.0835873 \\
\hline
\end{tabular}

Table 6. Complete consumption coefficient in 2010

\begin{tabular}{ccccc}
\hline Industry & Primary Industry & Secondary Industry & Tertiary Industry & Financial Industry \\
\hline Primary Industry & 0.2006053 & 0.1676965 & 0.0739595 & 0.028089 \\
Secondary Industry & 0.8278312 & 2.0345016 & 0.95169 & 0.421144 \\
Tertiary Industry & 0.1762232 & 0.3496679 & 0.3087343 & 0.3187593 \\
Financial Industry & 0.0299397 & 0.0627441 & 0.0619057 & 0.1054837 \\
\hline
\end{tabular}


Firstly, this paper investigates the complete dependence of the other industries to the financial industry by the horizontal analysis on the above table. In 2007, the financial industry itself consumes the largest amount of the complete financial inputs (0.0836), follows the tertiary industry (0.0578), the secondary industry (0.0545) and the primary industry (0.0275), it shows that the financial industry has a strongest complete promoting function to itself. In 2010, the financial industry itself also consumes the largest amount of the complete financial inputs (0.1055), follows the secondary industry $(0.0627)$, the tertiary industry $(0.0619)$ and the primary industry (0.0299). The complete consumption of each industry to the financial industry increases in all. It means that the financial industry has a stronger promoting function to each industry. And in 2010, the complete consumption of the financial products in the secondary industry is higher than the tertiary industry. It shows that the promoting function of the financial industry to the secondary industry has remarkable strengthened.

Through the longitudinal analysis of the table above, this paper investigates the complete dependence of the financial industry to the other industries. In 2007, the quantity of the products that the financial industry completely consumes is the secondary industry $(0.4076)$, the tertiary industry $(0.2768)$, the financial industry $(0.0836)$ and the primary industry $(0.0252)$ in turn. It is noticed that there is no direct link between the financial industry and the primary industry, so the 0.0252 here is the entire indirect link between them. And the complete consumption of the financial industry to itself is also low; it shows that the indirect internal link of the financial industry is low. It is due to the separate operation of the financial industry in our country. In 2010, the quantity of the products that the financial industry completely consumes is the secondary industry (0.4211), the tertiary industry $(0.3188)$, the financial industry $(0.1055)$ and the primary industry $(0.0281)$. From the data in 2007 and 2010 , it can be seen that the production of the financial industry needs to completely consume the products from the secondary industry most, and this is different from the direct link between the financial industry and the other industries.

\subsection{Analysis on the Spread Effect between the Financial Industry and the Three Major Industries}

Due to the complex associations between the industries, the change of one industry will have different degrees of spread effects on the other industries. In this paper, the influence coefficient is used to analyze the degree of the spread effect of the financial industry on the other industries, and the response coefficient is used to analyze the degree of the spread effect of the other industries on the financial industry.

\subsubsection{Analysis on the Spread Effect of the Financial Industry on the Other Industries}

The influence coefficient reflects the degree of the spread effect of the production of one industry to the other industries; it shows the degree of the influence of this industry on the other industries. The influence coefficient is the important basis to determine the dominant industry; it means that if the coefficient of this industry is greater than 1, the degree of the effect of this industry to the other industries is higher than the social average level; on the contrary, it means that the degree of the effect is less than the social average level. The greater the influence coefficient is, the greater the pulling function to the other industries is, and the backbone role in the national economy is stronger (Ying-fei Lv, 2012). The calculation formula of the influence coefficient is as follows:

The influence coefficient $=\frac{\text { the average value of the column coefficient of one industry in leotief inverse matrix }}{\text { the average value of the column coef ficient of all industries in leotief inverse matrix }}$

The influence coefficient of the financial industry calculated by the formula above is listed in Table 7 :

Table 7. Influence coefficient table

\begin{tabular}{ccc}
\hline & 2007 & 2010 \\
\hline Primary Industry & 0.8809 & 0.8833 \\
Secondary Industry & 1.4219 & 1.4288 \\
Tertiary Industry & 0.9824 & 0.9472 \\
Financial Industry & 0.7148 & 0.7406 \\
\hline
\end{tabular}

The influence coefficient of the financial industry is 0.7148 in 2007 and 0.7406 in 2010, both are less than 1; it shows that the influence of the financial industry to other industries is less than the social average level. And the pulling function of the financial industry to other industries is not obvious because the influence coefficient of the financial industry is less than the coefficient of other industries. However, the influence coefficient of the financial industry is on the rise; it shows that the pulling function of the financial industry to other industries increases year by year. 


\subsubsection{Analysis of the Spread Effect of the Other Industries on the Financial Industry}

The response coefficient reflects the degree of the demand of one industry to the other industries. The greater the response coefficient is, showed that the demand response of this industry to the economy development is stronger, and the pulling function of the other industries to this industry is stronger. Generally speaking, the response coefficient is higher at the rapid economic growth period. The calculation formula of the response coefficient is as follows:

$$
\text { The response coefficient }=\frac{\text { the average value of the row coef ficient of one industry in leotief inverse matrix }}{\text { the average value of the row coefficient of all industries in leotief inverse matrix }}
$$

The response coefficient of the financial industry calculated by the formula above is listed in Table 8 :

Table 8. Response coefficient table

\begin{tabular}{ccc}
\hline & 2007 & 2010 \\
\hline Primary Industry & 0.5837 & 0.5812 \\
Secondary Industry & 2.1060 & 2.0694 \\
Tertiary Industry & 0.8227 & 0.8512 \\
Financial Industry & 0.4876 & 0.4981 \\
\hline
\end{tabular}

The response coefficient of the financial industry is 0.4876 in 2007 and 0.4981 in 2010, both are less than the coefficient of the other industries at the same period, it shows that the pulling function of the other industries to the financial industry is not obvious.

\subsubsection{Brief Summary}

It can be found from the analysis above that the influence coefficient and the response coefficient of the financial industry are both less than 1; it shows that the supply promoting function and the demand pulling function of the financial industry to the three major industries are both not obvious. It shows that the contribution of the financial industry to the national economy is small, and the development of the financial industry can't promote the development of the other industries fully. There is a long way to go before the financial industry becomes a pillar industry, but it also shows that the financial industry has a huge development space in the future.

\subsection{Analysis on the Intermediate Input Rate and the Intermediate Demand Rate of the Financial Industry}

The intermediate input rate and the intermediate demand rate are the indexes that reflects the industrial relevancy, generally be used to determine the position of the industry at the economic system.

\subsubsection{Analysis on the Intermediate Input Rate of the Financial Industry}

The intermediate input rate is the ratio of the intermediate inputs and the total inputs; it reflects the proportion of a certain industry that consumes the intermediate products from other industries (including the industry itself). The calculation formula of the rate is as follows:

$$
F_{j}=\frac{\sum_{i=1}^{n} x_{i j}}{\sum_{i=1}^{n} x_{i j}+D_{j}+N_{j}}(j=1,2, \ldots n)
$$

In this formula, $D_{j}$ represents depreciation of fixed assets of the industry; $N_{j}$ represents the value created by the industry, consisting of the labor reward, net product tax and the operating surplus. Due to the sum of the intermediate input rate and the value-added rate is 1, the higher the intermediate input rate of the industry is, the lower the value-added rate (sum of the depreciation and the net salvage) of the industry is. It is generally believed that the industry whose intermediate input rate is above $50 \%$, it is the "low value-added and high driving capability" industry; on the contrary, is the "high value-added and low driving capability" industry (Ying-fei Lv, 2012). The intermediate input rate of the financial industry and the three major industries is calculated by the formula and listed in the Table 9:

Table 9. Intermediate input rate table

\begin{tabular}{ccc}
\hline & 2007 & 2010 \\
\hline Primary Industry & 0.4138 & 0.4153 \\
Secondary Industry & 0.7671 & 0.7783 \\
Tertiary Industry & 0.4826 & 0.4609 \\
Financial Industry & 0.3105 & 0.3502 \\
\hline
\end{tabular}


The intermediate input rate of the financial industry is 0.3105 in 2007, less than $50 \%$, and less than the three major industries obviously; it shows that the financial industry is a high value-added industry, but the capability of promoting the other industries is low. Combined with the data of 2010, it is found that the intermediate input rate of the financial industry is on the rise.

\subsubsection{Analysis on the Intermediate Demand Rate of the Financial Industry}

The intermediate demand rate is the ratio of the intermediate demands and the total demands; it reflects the degree of the products from a certain industry demanded by the other industries (including the industry itself). The calculation formula is as follows:

$$
G_{j}=\frac{\sum_{j=1}^{n} x_{i j}}{\sum_{j=1}^{n} x_{i j}+Y_{i}}(i=1,2, \ldots n)
$$

In this formula, $Y_{i}$ represents the final products of the industry, which is the amount of the products that used to be consumed. The higher the rate is, the more capital goods that the industry provides. Generally speaking, the industry whose intermediate demand rate is higher than $50 \%$ is the industry that mainly provides productive services and the industry whose intermediate demand rate is less than $50 \%$ is the industry that mainly provides life services (Ying-fei \& Yan-li, 2012). The rate calculated by the formula above is listed is the Table 10:

Table 10. Intermediate demand rate table

\begin{tabular}{ccc}
\hline & 2007 & 2010 \\
\hline Primary Industry & 0.7024 & 0.7777 \\
Secondary Industry & 0.7328 & 0.7270 \\
Tertiary Industry & 0.4665 & 0.4834 \\
Financial Industry & 0.7472 & 0.7747 \\
\hline
\end{tabular}

The intermediate demand rate of the financial industry is 0.7472 in 2007 , higher than $50 \%$; it shows that the financial industry mainly provides productive services to meet the demand of the intermediate products of the other industries. It can be found that the intermediate demand rate of the tertiary industry besides the financial industry is 0.4665 ; it shows that the tertiary industry besides the financial industry mainly provides life services, and this is an important difference between the financial industry and the other tertiary industry. Combined with the data of 2010, it is found that the intermediate demand rate of the financial industry is on the rise.

\subsubsection{Brief Summary}

It can be found from the analysis above that the financial industry is a high value-added industry and mainly provides productive services. However, the promoting function of the financial industry to the other industries is low, so the financial industry may become a bottleneck industry restricting the development of the national economy. So China should develop the financial industry vigorously and pay attention to the inosculation of the financial industry and the other industries at the same time.

\section{Conclusions and Suggestions}

\subsection{Conclusions}

There are five conclusions in the analysis of the direct dependency:

1). The financial industry has a strongest direct influence on itself, and its direct promoting role to the three major industries is on the rise.

2). The development of the financial industry doesn't need the direct consumption of the products from the primary industry, and mainly needs the direct inputs of the tertiary industry.

$3)$. The financial industry is a high value-added industry.

4). The financial industry has a great economic benefit.

5). The financial industry has a great need of talents.

There are two conclusions in the analysis of the complete dependency:

1). The financial industry has a strongest complete promoting role to itself. And it has a stronger and stronger complete promoting role to the secondary industry.

2). The financial industry has a low complete consumption on itself; it shows that the internal indirect relevancy 
in the financial industry is low because of the separate operation in China. The financial industry completely consumed the products from the secondary industry mostly.

There are three conclusions in the analysis of the spread effect:

1). Based on the analysis on the influence coefficient, it is found that the pulling role of the financial industry to the other industries is not obvious, but the coefficient is on the rise, it shows that the pulling role to the other industries is on the rise.

2). Based on the analysis on the response coefficient, it is found that the pulling role of the other industries to the financial industry is not obvious.

3). Both of the influence coefficient and the response coefficient are less than 1, it indicates that the supply promoting role and the demand pulling role of the financial industry to the three major industries are not obvious.

In the analysis of the intermediate input rate and intermediate demand rate, it is found that the financial industry is a high value-added industry and an industry that mainly provides the productive services. However, the promoting role of the financial industry to the other industries is low, so the financial industry may become a bottleneck industry restricting the development of the national economy.

In conclusion, although the financial industry has a rapid development in China, its position and role in the national economy is still not outstanding. There is still a long way to go before the financial industry becomes a pillar industry.

\subsection{Suggestions}

There are several suggestions proposed according to the above conclusions in this paper:

1). To play the pulling role of the financial industry to the national economy effectively, China should improve the industrial structure of the financial industry to promote its development.

2). Due to the development of the financial industry has a great need of the direct input of the tertiary industry and the complete input of the secondary industry, China should put the development of the tertiary industry and the improvement of the secondary industry as a top task in order to improve the development of the financial industry.

3). China should speed up the cultivation of the financial talent in order to develop the financial industry due to the development of the financial industry has a great need of talents.

4). The financial industry has a great economic benefit, but it is easy to become a bottleneck industry restricting the development of the national economy. So China must put the development of the financial industry as an important task in the period of the economic transition so as to play the promoting role of the financial industry to the real economy effectively.

\section{References}

Jie, B. (2014). The Input-output Analysis of the Financial Industry in Jiangsu Province. Economic Research Guide, (29), 83-87. http://dx.doi.org/10.3969/j.issn.1673-291X.2014.29.034

Leontief, W. (1936). Quantitative Input and Output Relations in the Economic System of the United States. Review of Economics and Statistics, (3), 105-125. http://dx.doi.org/10.2307/1927837

Mei-dong, Q., \& Xian-fa, K. (2011). The Mechanism Analysis on the Financial Support for the Circular Economy Development Based on the Input-Output Model. Economic Problems, (10), 104-108. http://dx.doi.org/10.16011/j.cnki.jjwt.2011.10.023

Ming, L., Yuzhu, L., \& Tianyu, C. (2010). Analysis of the Impact of the Financial Industry on the Economic Development in Anhui Province on the Base of the Input-output Table. Business Economy, (13), 80-81. http://dx.doi.org/10.3969/j.issn.1009-6043.2010.13.036

Shi-gai, C. (2013). The Research of Industry Financial of China: Based on Input-output Technology. Statistics \& Information Forum, 28(3), 38-42. http://dx.doi.org/10.3969/j.issn.1007-3116.2013.03.007

Shouyi, Z., \& Xinquan, G. (1988). Input-output Optimization Model of the Embedded Industry Departments. Research of Quantitative Economics and Technological Economics, (12), 34-41. http://dx.doi.org/10.13653/j.cnki.jqte.1988.12.006

Xikang, C. (1992). Input Occupancy Output Analysis on China's Urban and Rural Economy. Beijing: Science Press. 
Yingfei, L. (2012). Input-output Relevancy and Efficiency Analysis on China's Financial Industry. Jilin University, 2012.

Yingfei, L., \& Yanli, S. (2011). Influence of Input-output of Financial Industry on Economic Growth in Jilin Province. Taxation and Economy, (4), 109-112.

Zhanqi, Y. (2005). Comparison of the Interrelation between the Financial Service Industry and Others. Industrial Economy Research, (5), 35-42.

\section{Copyrights}

Copyright for this article is retained by the author(s), with first publication rights granted to the journal.

This is an open-access article distributed under the terms and conditions of the Creative Commons Attribution license (http://creativecommons.org/licenses/by/3.0/). 